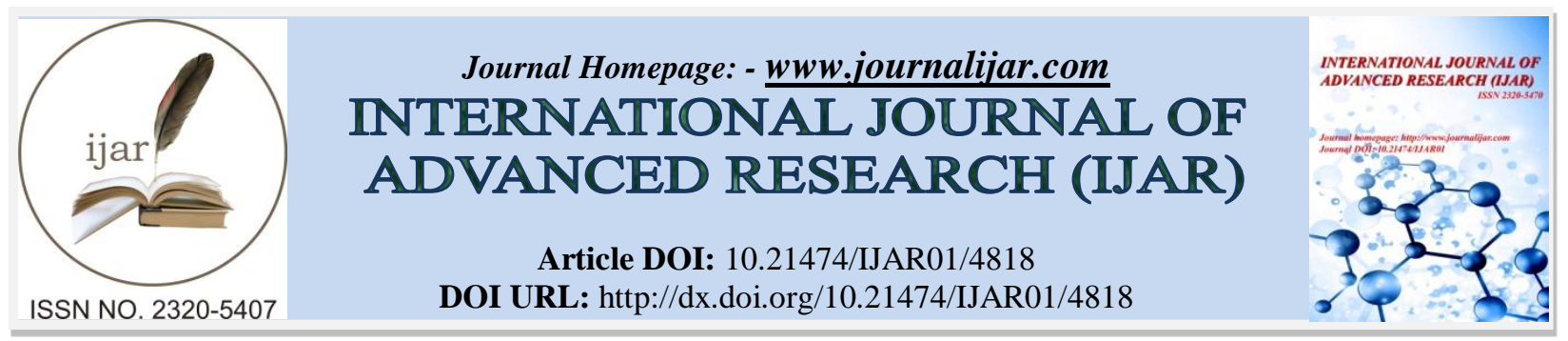

RESEARCH ARTICLE

\title{
ISOLATION AND MOLECULAR IDENTIFICATION OF STAPHYLOCOCCUS SPP. FROM BOVINE MASTITIS MILK SAMPLES.
}

\section{Khushal Patel ${ }^{1}$, Chaitanya Joshi ${ }^{2}$ and ${ }^{*}$ Anju Kunjadiya ${ }^{3}$.}

1. Ashok \& Rita Patel Institute of Integrated Study \& Research in Biotechnology and Allied Sciences, New Vallabh Vidyanagar-388121, Gujarat, India.

2. Department of Animal Biotechnology, College of Veterinary Science and A. H., Anand Agricultural University, Anand-388001, Gujarat, India.

3. Center for Interdisciplinary Studies in Science and Technology, Sardar Patel University, Vallabh Vidyanagar388121, Gujarat, India.

\section{Manuscript Info}

Manuscript History

Received: 11 May 2017

Final Accepted: 13 June 2017

Published: July 2017

Key words:-

Staphylococcus; MRSA, Mastitis,

Somatic Cell Count, 23S

\section{Abstract}

Mastitis is an inflammation of mammary gland caused by major etiological agent Staphylococcus sp. mainly antibiotic resistant strains. In this study, antibiotic resistant Staphylococcus spp. were isolated, characterized and confirmed by molecular techniques from a total of 120 lactating cows including 30 buffaloes (480 quarter milk samples). They were screened for mastitis using Somatic Cell Count (SCC) and California Mastitis Test (CMT). Isolation and identification of Staphylococcus spp. was done using standard microbiological methods by species specific media as well as various biochemical tests. Antibiotic susceptibility tests (ABST) were performed to screen resistant isolates. Genotypic identification was confirmed using $23 \mathrm{~S}$ rRNA amplification and 16S rDNA sequencing. A total of 193 nonduplicated Staphylococcus spp. were isolated having higher than 500 somatic cells $/ \mu 1$ and CMT score was 1 or 2 . Methicillin resistance in 31 and other multidrug resistivity in 17 Staphylococcus spp. were observed. Multidrug resistant strains were identified using Sanger sequencing and assigned accession number KX821621 to KX821638 for 11 Staphylococcus aureus and 7 coagulase negative Staphylococcus spp. These findings suggested that milk represents a potential infection risk threat of multidrug-resistant $S$. aureus in India due to neglected hygienic practices during lactation and maintenance of herd.

\section{Introduction:-}

Mastitis infection in bovines is a critical and a stubborn intramammary infection (IMI), producing economic losses; drop in milk production, increased cost of treatment and culling process (Abd-Elrahman 2013). In dairy animals, Staphylococcus spp. are most ubiquitous pathogen specially Staphylococcus aureus is the one causing mastitis infections (Mullen et al. 2013). 
Natural immunity to fight against environment of $S$. aureus has been detected in clinical and subclinical bovine mastitis cases (Davis MP and Gamier P. 2013). Staphylococcus aureus infection causes main concern regarding treatment using experimental antimicrobials and leads challengeable tasks for veterinarians. Intramammary infections in animal caused by methicillin-resistant staphylococci (MRS) are indeed challenging task which include health risk of animal as well as milkers (Gómez et al. 2015).

Coagulase negative Staphylococcus spp. (CNS), which are in acquisition of interest for researchers because of its augmented exposure as an infection causing agents including human (Embden and Barkema 2009). At present, CNS are generally deliberated to be opportunistic pathogens in the research field. Epidemiology of CNS is not clear, which is sole reason for not having treatment against this pathogen. CNS group consists of about 40 different Staphylococcus species (Shittu and Lin 2006).

Majority of mastitis causing pathogens are normally found intermediate resistant to the antimicrobials used for treatment, but in past two decades few studies have signposted an augmented resistance of $S$. aureus and CNS to $\beta$ lactam antibiotics (Trojan et al. 2016). In a view of this, the emergence of methicillin resistance among Staphylococcus spp. isolated from bovine milk has been reported in different countries and continents (Bergonier et al. 2014).

The surveillance of methicillin-resistant Staphylococci should be prioritized because the accurate diagnosis of these bacteria is paramount for appropriate mastitis treatment. The purpose of this study was to identify and characterize multidrug resistant including methicillin in Staphylococcal isolates from bovine mastitis milk samples.

\section{Methodology:-}

\section{Sample collection and processing:-}

A total of 480 quarters milk samples from 120 lactating cows and buffaloes were collected from the different regions of Anand and Kheda district in Gujarat. Sample collection was done by maintaining proper hygiene conditions as described (Patel et al. 2017), At beginning, few drops of milk were discarded and samples were collected in autoclaved 50mL falcon tube (Tarson). California Mastitis Test was executed to check infections level simultaneously (Bhutto et al. 2012). Samples were brought to the laboratory in desired cooling condition and subjected to further microbiology evaluation. Somatic cells present in milk sample were analyzed on Fossomatic ${ }^{\mathrm{TM}}$ Cell Minor (Foss, Denmark) (Bhutto et al. 2012).

\section{Isolation of Staphylococci and culture Conditions:-}

For isolation of Staphylococci, milk samples were diluted and streaked on Baird-Parker agar base (Himedia, Catalog No. M043, India) plate with added $3.5 \%$ potassium tellurite and incubated at $37^{\circ} \mathrm{C}$ for 24 to $36 \mathrm{~h}$. S. aureus colonies were identified on the basis of colony morphology as mentioned in Himedia reference (Oliveira et al. 2011). Such colonies were further transferred to mannitol salt agar (Himedia, Catalog No. MH118, India) for differentiation and selection of pathogenic Staphylococcus aureus and Staphylococci sp. (Kateete et al. 2010). Confirmed isolates were cultured in Luria Broth (Himedia M575, India) at $37^{\circ} \mathrm{C}$ with aeration and $25 \%$ glycerol stocks were prepared for storage purpose. Isolates were further confirmed as $S$. aureus by a coagulase test using coagulase rabbit plasma (HiMedia, FD248) and species specific biochemical tests. Gram's morphology was also observed by preparing smear from the isolated culture on clean grease free microscopic glass slide and stained with gram's method of staining (Carles et al. 2004).

\section{Biochemical examination:-}

Various biochemical tests specific for confirmatory Staphylococcus sp. identification named methyl red test, VogesProskauer test, hemolytic test, catalase test, urea hydrolysis, indole and ammonia production were performed for characterization of isolates (Makki 2011).

\section{Antibiotic susceptibility test:-}

According to the National Committee of Clinical Laboratory Standards (NCCLS), an in vitro antibiotic susceptibility for isolated Staphylococci were checked against 20 different antibiotics by agar disc diffusion method (Carey et al. 2010). Antibiotic disc were used according to manufacturer's instructions, Himedia, India. Antibiotics used in this study were, amoxycillin (10 mcg/disc), ampicillin (10 mcg/disc), cfataxime (30 mcg/disc), chloramphenicol (30 mcg/disc), ciprofloxacin $(5 \mathrm{mcg} / \mathrm{disc})$, cloxacillin (10 mcg/disc), enrofloxacin (10 mcg/disc), erythromycin $(15 \mathrm{mcg} / \mathrm{disc})$, gentamicin $(10 \mathrm{mcg} / \mathrm{disc})$, kanamycin $(30 \mathrm{mcg} / \mathrm{disc})$, meropenem $(10 \mathrm{mcg} / \mathrm{disc})$, 
methicillin $(5 \mathrm{mcg} / \mathrm{disc})$, nalidixic acid $(30 \mathrm{mcg} / \mathrm{disc})$, ofloxacin $(5 \mathrm{mcg} / \mathrm{disc})$, oxacillin $(1 \mathrm{mcg} / \mathrm{disc})$, penicillin-G $(10 \mathrm{mcg} / \mathrm{disc})$, rifampicin $(5 \mathrm{mcg} / \mathrm{disc})$, streptomycin $(10 \mathrm{mcg} / \mathrm{disc})$, tetracycline $(30 \mathrm{mcg} / \mathrm{disc})$, vancomycin $(30$ $\mathrm{mcg} / \mathrm{disc})$.

\section{Extraction of genomic DNA:-}

DNA was extracted from $24 \mathrm{hr}$ grown Staphylococcal cultures using Proteinase-K-SDS method mentioned with slight modification(Prosperi et al. 2013). Concisely, $400 \mu \mathrm{l}$ of culture was taken, centrifuged at $8000 \mathrm{rpm}$, supernatant was removed and dissolved in $500 \mu \mathrm{l}$ TE buffer $(10 \mathrm{~mm}$ of Tris $\mathrm{HCl}, 1 \mathrm{mM}$ of EDTA, pH 8.0). Treatment of lysozyme (Sigma-Aldrich), $10 \% \mathrm{w} / \mathrm{v}$ freshly prepared SDS and $10 \mu$ proteinase-k $(10 \mathrm{mg} / \mathrm{ml})$ (SigmaAldrich) was given t culture and incubated at $37^{\circ} \mathrm{C}$ for $1 \mathrm{hr}$. Subsequently, addition of $10 \% \mathrm{w} / \mathrm{v} \mathrm{CTAB}$ and $200 \mu \mathrm{l}$ $\mathrm{NaCl}(5 \mathrm{M})$ in the suspension and was re-incubated for $10 \mathrm{~min}$ at $56{ }^{\circ} \mathrm{C}$ in boiling water bath. The undesirable contaminants that are chiefly made of proteins were removed by Phenol: Chloroform: isoamyl alcohol (25:24:1) and Chloroform: isoamyl alcohol (24:1). $100 \mu \mathrm{l}$ of 5M sodium acetate is added to the contents and is mixed gently. The salts and alcohol remnants are removed by washing with $80 \%$ alcohol. After removal of alcohol by centrifugation, desiccated the tubes and elution was done in $50 \mu \mathrm{l}$ warm TE buffer. Quantity of extracted DNA was checked using Nanodrop 1000 (ThermoScientific, USA) and quality on $0.8 \%$ agarose gel in $0.5 \mathrm{X}$ TBE (Tris $45 \mathrm{mM}$, Boric acid 45 $\mathrm{mM}$, EDTA $1 \mathrm{mM}$ ) buffer (pH 8.0). DNA was stored at $-20^{\circ} \mathrm{C}$.

Species specific identification through $23 S$ rRNA gene amplification:-

Amplicons of 23S $r R N A$ gene were produced by species specific forward primer: 5'-ACG GAG TTA CAA AGG ACG AC-3' and Reverse Primer: 5'-AGC TCA GCC TTA ACG AGT AC-3' (Coelho et al. 2011). Each PCR mixture $(25 \mu \mathrm{l})$ consisted of PCR Taq Buffer with MgCl2 $(2.5 \mu \mathrm{l}), 2.5 \mathrm{mMdNTP}$ mix $(2.5 \mu \mathrm{l}), 0.2 \mathrm{U}$ of Taq DNA polymerase (Genei, Bangalore, India), $1 \mu \mathrm{l}$ of each forward and reverse primer $(10 \mathrm{pM} / \mu \mathrm{l})$ each, and $16.7 \mu \mathrm{l}$ molecular biology grade water by using PCR program slightly modified by initial denaturation at $94^{\circ} \mathrm{C}$ for 3 min followed by 28 cycles of denaturation, annealing, extension $\left(94^{\circ} \mathrm{C}\right.$ for 60 seconds, $57^{\circ} \mathrm{C}$ for 60 seconds, $72^{\circ} \mathrm{C}$ for 60 seconds), and final extension at $72^{\circ} \mathrm{C}$ for $5 \mathrm{~min}$ followed by hold at $4^{\circ} \mathrm{C}$ (Khichar et al. 2014).

\section{S rDNA amplification:-}

16S rDNA amplification was carried out using universal primer 8-F (5'AGAGTTTGATCCTGGCTCAG3') and 926R (5'CCGTCAATTCCTTTGAGTTT3'). PCR amplification cycle consisted of initial denaturation step of 3 min at $94{ }^{\circ} \mathrm{C}$, followed by 25 cycles of 40 seconds at $94{ }^{\circ} \mathrm{C}, 45$ seconds at $54{ }^{\circ} \mathrm{C}$, and 75 seconds at $72{ }^{\circ} \mathrm{C}$. Following amplification, final extension was performed at $72{ }^{\circ} \mathrm{C}$ for $3 \mathrm{~min}$ and cooled at $4{ }^{\circ} \mathrm{C}$ (Patel et al. 2016). Amplified PCR product was confirmed using $1.5 \%$ agarose gel electrophoresis (Türkyilmaz et al. 2010). A DNA marker of known DNA fragment sizes (500 bp ladder) was run alongside the specimens to aid in identification of the products. Desired amplified product was cut from the gel and purified using QIAGEN gel purification kit (QIAGEN, Germany) (Bergonier et al. 2014).

\section{Nucleotide sequencing:-}

Purified 16S products of isolates which includes, multidrug resistivity against conventional antibiotics (ABST assay) and positive 23S rRNA gene amplification were sent for Sanger deodoxy sequencing (SciGenome Pvt. Ltd., Kerala). Obtained Sequences were blasted with the GenBank NCBI nr database (http://www.ncbi.nlm.nih.gov/). The highest identity was selected as the identified and according to the results, sequences were submitted for species assignment (Hijazin et al. 2011).

\section{Results:-}

Out of total 120 animals harboring 480 quarter milk samples, 128 (26.66\%) and 52 (10.83\%) were positive for CMT score 1 and 2 respectively. SCC score more than 500 cells/ $\mu 1$ was found in 140 (29.17) quarters (Table 1). Milk samples from these contagious quarters were proceeded further for isolation of Staphylococcus spp.

\section{Isolation and characterization of Staphylococcus spp:-}

193 non-duplicate Staphylococcus spp. were identified on the basis of colony morphology on Baird-Parker agar (Figure 1). On mannitol salt agar a total of 139 (72.02\%) (Pink to yellow positive pigmentation) and 40 (20.73\%) (Pink pigmentation) were differentiated (Figure 2). Gram positive cocci were observed in Gram's staining. Positive results for different specific biochemical tests viz. Methyl Red test, Voges- Proskauer test, Hemolytic test, Catalase test, Urea hydrolysis, Indole and Ammonia production test were obtained. Positive coagulase test in 121 isolates and negative in 28 isolates were found. 
Screening of methicillin-resistant Staphylococcus spp. (MRS):-

On the basis of antibiotic resistivity pattern, multidrug resistivity of isolates were observed mainly against methicillin, oxacillin, tetracyclin and vancomycin. A total of 31 (22.30\%) MRSA (Methicillin Resistant Staphylococcus aureus) out of 139 S. aureus and methicillin resistant in 17 (42.5\%) Staphylococcus spp. were observed (Table 2). Fascinatingly, S.aureus and Staphylococcus spp. showed sensitivity to gentamicin (15.11\%, $17.50 \%)$, ampicillin $(15.83 \%, 10 \%)$ and least enrofloxacin $(10.79 \%, 52.50 \%)$ respectively. Interestingly, all the rest organisms exhibited intermediate response to antibiotics. Some of which are rampantly used in the treatment of various disorders of bovines including mastitis.

Genomic DNA Isolation, 23S rRNA and 16S rDNA gene amplification:-

Electrophoresis of genomic DNA having concentration above $60 \mathrm{ng} / \mu \mathrm{l}$ of bacteria under UV transilluminator is shown in figure 3. An Amplicon of $1250 \mathrm{bp}$ size of $23 \mathrm{~S} \mathrm{rRNA}$ gene and $850 \mathrm{bp}$ of $16 \mathrm{~S} r D N A$ gene was observed as shown in figure 4 and 5.

Identification of isolates using $16 \mathrm{~S}$ rDNA sequencing:-

Output sequences of sanger dideoxy sequencing were submitted to GenBank under the accession number KX821628 to KX821638 for Staphylococcus aureus (11 strains) and KX821621 to KX821627 for coagulase negative Staphylococcus spp (07 strains).

Table 1:- Results of CMT and SCC of collected Milk samples

\begin{tabular}{|c|c|c|c|c|c|c|}
\hline \multirow{2}{*}{ No. of Cow } & \multirow{2}{*}{ Quarters } & \multicolumn{3}{|c|}{ CMT (Score) } & \multicolumn{2}{c|}{ SCC } \\
\cline { 3 - 7 } & & Negative & $\mathbf{1}$ & $\mathbf{2}$ & $\mathbf{0 - 5 0 0}$ cells/ $\boldsymbol{\mu l}$ & $>\mathbf{5 0 0}$ cells/ $\boldsymbol{\mu l}$ \\
\hline \multirow{2}{*}{120} & \multirow{2}{*}{480} & 300 & 128 & 52 & 340 & 140 \\
\cline { 3 - 7 } & & $62.50 \%$ & $26.67 \%$ & $10.83 \%$ & $70.83 \%$ & $29.17 \%$ \\
\hline
\end{tabular}

(CMT: California Mastitis Test, SCC: Somatic Cell Count)

Table 2:- Antibiotic Susceptibility test results

\begin{tabular}{|c|c|c|c|c|}
\hline \multirow[b]{2}{*}{ Antibiotics } & \multicolumn{2}{|c|}{ \% Resistant } & \multicolumn{2}{|c|}{ \% Sensitive } \\
\hline & $\begin{array}{l}\text { S. aureus } \\
(139)\end{array}$ & $\begin{array}{c}\text { Staphylococcus } \\
\text { spp. (40) }\end{array}$ & S. aureus (139) & $\begin{array}{c}\text { Staphylococcus } \\
\text { spp. (40) }\end{array}$ \\
\hline Amoxycillin $(10 \mu \mathrm{g})$ & 0 & 0 & 0 & 0 \\
\hline Ampicillin $(10 \mu \mathrm{g})$ & $13(9.35 \%)$ & $8(20 \%)$ & $22(15.83 \%)$ & $4(10 \%)$ \\
\hline Cfataxime $(30 \mu \mathrm{g})$ & 0 & 0 & 0 & 0 \\
\hline Chloramphenicol $(30 \mu \mathrm{g})$ & 0 & 0 & 0 & 0 \\
\hline Ciprofloxacin $(5 \mu \mathrm{g})$ & $41(29.49 \%)$ & $22(55 \%)$ & 0 & 0 \\
\hline Enrofloxacin $(10 \mu \mathrm{g})$ & 0 & 0 & $15(10.79 \%)$ & $21(52.5 \%)$ \\
\hline Erythromycin $(15 \mu \mathrm{g})$ & 0 & 0 & 0 & 0 \\
\hline Gentamicin $(10 \mu \mathrm{g})$ & $35(25.18 \%)$ & $10(25 \%)$ & $21(15.11 \%)$ & $7(17.5 \%)$ \\
\hline Kanamycin $(30 \mu \mathrm{g})$ & $18(12.95 \%)$ & $13(32.5 \%)$ & 0 & 0 \\
\hline Meropenem $(10 \mu \mathrm{g})$ & 0 & 0 & 0 & 0 \\
\hline Methicillin (5 $\mu \mathrm{g})$ & $31(22.30 \%)$ & $17(42.5 \%)$ & 0 & 0 \\
\hline Nalidixic acid (30 $\mu \mathrm{g})$ & $21(15.11 \%)$ & $7(17.5 \%)$ & 0 & 0 \\
\hline Cloxacilin $(10 \mu \mathrm{g})$ & $38(27.34 \%)$ & $11(27.5 \%)$ & 0 & 0 \\
\hline Ofloxacin $(5 \mu \mathrm{g})$ & $27(19.42 \%)$ & $17(42.5 \%)$ & 0 & 0 \\
\hline Oxacillin $(1 \mu \mathrm{g})$ & $23(16.55 \%)$ & $9(22.5 \%)$ & 0 & 0 \\
\hline Rifampicin $(5 \mu \mathrm{g})$ & $45(32.37 \%)$ & $21(52.5 \%)$ & 0 & 0 \\
\hline Streptomycin $(10 \mu \mathrm{g})$ & $33(23.74 \%)$ & $16(40 \%)$ & 0 & 0 \\
\hline Tetracycline $(30 \mu \mathrm{g})$ & $17(12.23 \%)$ & $6(15 \%)$ & 0 & 0 \\
\hline Penicillin-G $(10 \mu \mathrm{g})$ & $22(15.83 \%)$ & $12(30 \%)$ & 0 & 0 \\
\hline Vancomycin $(30 \mu \mathrm{g})$ & $20(14.39 \%)$ & $14(35 \%)$ & 0 & 0 \\
\hline
\end{tabular}

(Sensitivity was observed against Ampicillin, Enrofloxacin and Gentamicin Only) 


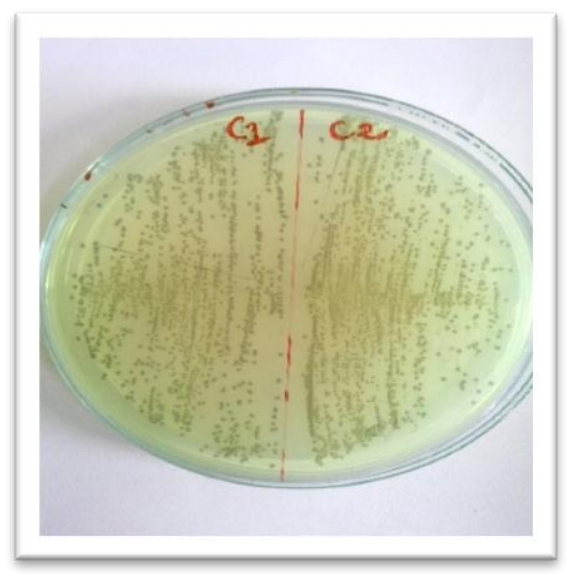

Figure 1:- Representative image of baird-parker agar plate showing black colored Staphylococcus spp.

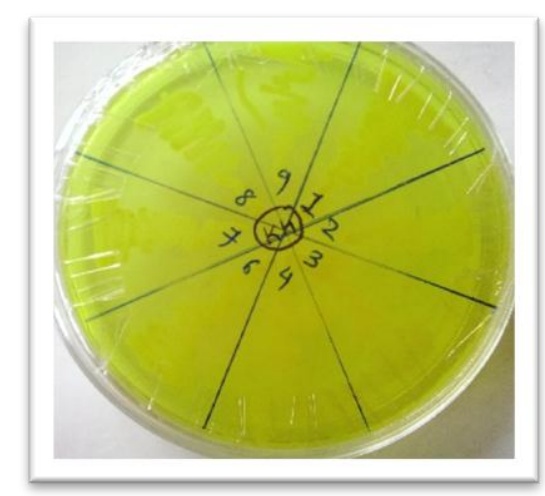

Figure 2:- Representative image of mannitol salt agar plate showing positive fermentation by color change from pink to yellow; indicate $S$. aureus

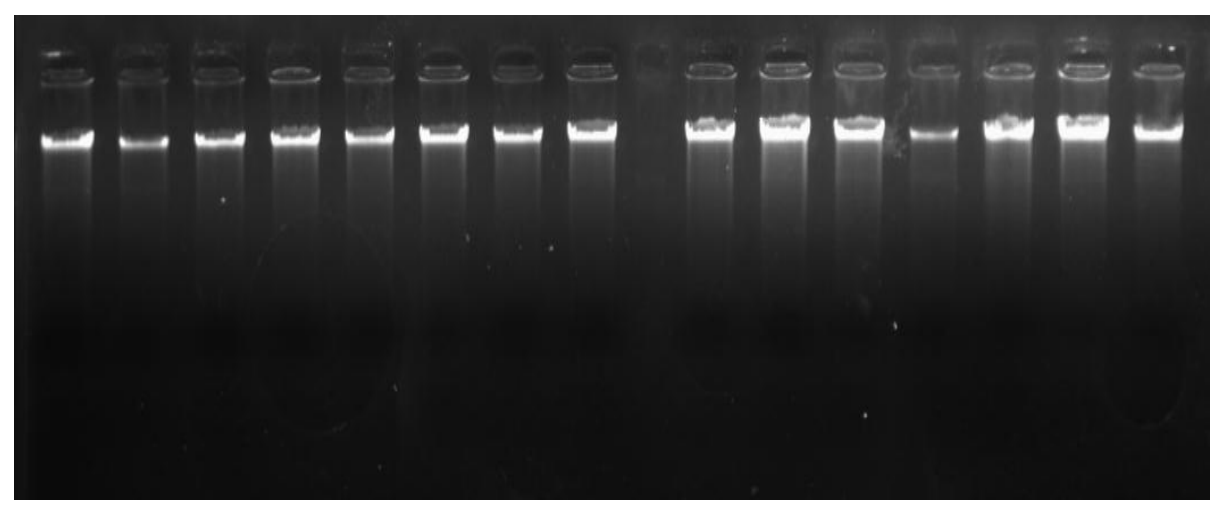

Figure 3:- Agarose gel (0.8\%) showing isolated genomic DNA in UV transilluminator 


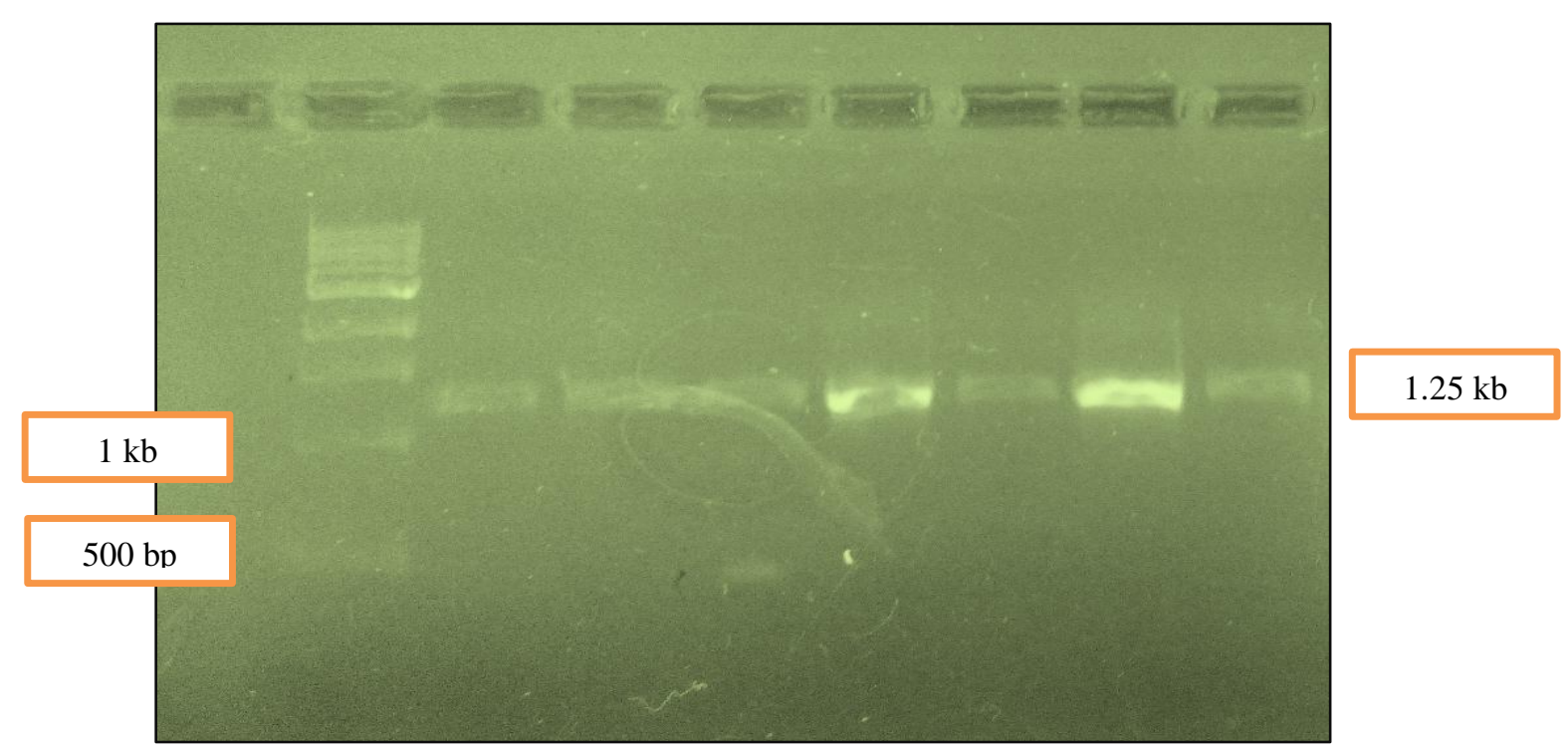

Figure 4:- Agarose gel (1.5\%) showing amplified product $23 S$ rRNA gene under UV transilluminator with $1 \mathrm{~kb}$ ladder, Product size seems to be approx. $1250 \mathrm{bp}$

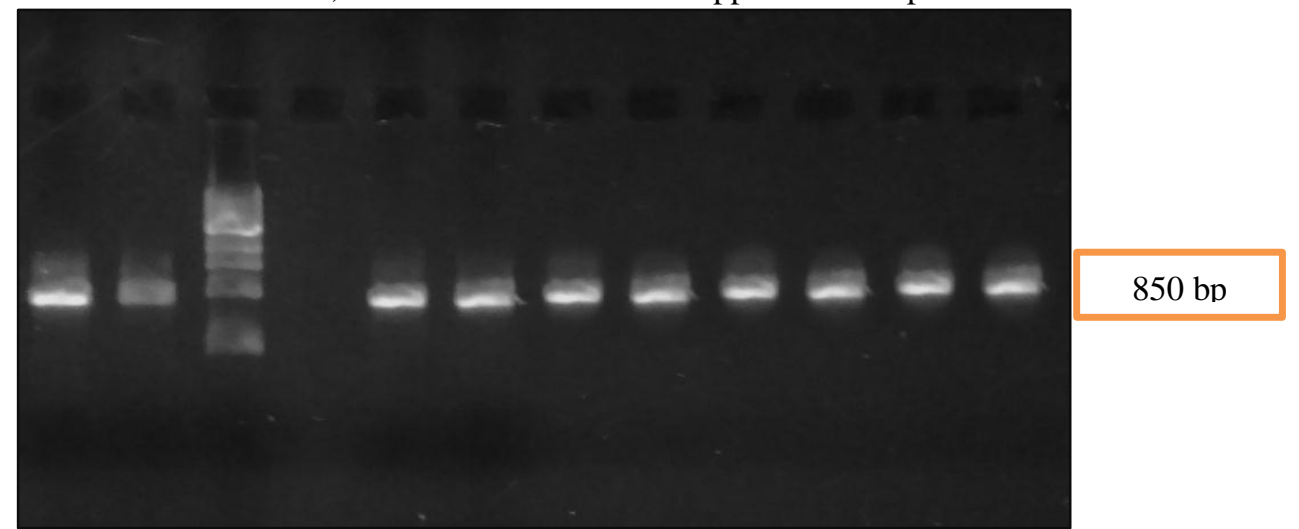

Figure 5:- Agarose gel (1.5\%) showing amplified product $16 \mathrm{~S} r D N A$ gene under UV transilluminator with $1 \mathrm{~kb}$ ladder, Product size seems to be approx. $850 \mathrm{bp}$.

\section{Discussion:-}

In this study, we have isolated multidrug resistant Staphylococcus spp. from bovine mastitis milk. Staphylococcus aureus remains one of the most significant micro-organisms associated with bovine mastitis worldwide. The isolation of MRSA from animals was first reported in 1972 (Devriese et al. 1972). For identification of bacteria, majority of the researchers tend to use isolation on selective media and molecular identification. In this study, biochemical characterization of each isolate was used to eliminate sequencing cost for molecular identification at later stage.

Since the use of antibiotic has been boundless in recent years, presence of MRSA in dairy farm has been recognized (Haran et al. 2012a). Many studies on prevalence of MRSA investigation have been reported in cattles in India; however, limited information with respect to the characterization of MRSA in cattle milk is available (Sumathi et al. 2008).

For veterinarians, one of the paramount microbial threats of the twenty-first century is developing antimicrobial resistance in pathogens. One of the pathogen, $S$. aureus has always been a stumbling block for antimicrobial chemotherapy and the introduction of new classes of antimicrobial agents is usually followed by the emergence of resistant forms of this pathogen (Shittu and Lin 2006; Harrison et al. 2013). Therefore, surveillance on the antimicrobial susceptibility patterns of $S$. aureus mainly methicillin resistant is of utmost importance in understanding new and emerging resistance trends and in the management. 
Our results suggest that there is a high prevalence of MRSA that is $22.30 \%$. Consistent with our findings, other countries have reported numerous rates of prevalence of MRSA in bovine milk. A study of S. aureus from mastitic cattle in India reported a high prevalence of MRSA, i.e., 13\% of $S$. aureus isolates (14 of 107 samples) which is quite differ from our result in which it shows prevalence of MRSA is $22.30 \%$ (31 of 139). Such high prevalence has not been reported in studies from the United States and Europe (Türkyilmaz et al. 2010; Bardiau et al. 2013). Such resistance against antibiotics is only the excessive use of $\beta$-lactam antibiotics that are used as primary choice of treatment provoking strong $\beta$ - lactamase producers $S$. aureus isolates (Saei 2012).

In a recent study of MRSA isolated from milk samples from mastitic cows, $100 \%$ of isolates were resistant to clindamycin, chloramphenicol, erythromycin, and gentamicin (Lee et al. 2015). In another study in Switzerland, two MRSA isolates from 142 milk samples from from mastitic cows were found resistant to all beta-lactam antibiotics (Haran et al. 2012b; Lange et al. 2015), while Vanderhaeghen et al. reported resistance to tetracycline, with frequent resistance to macrolides, lincosamide, and aminoglycosides, in MRSA from milk from mastitic cows (Bardiau et al. 2013).

The CoNS species in our data, S. hominis and S. pasteuri has been reported most frequently in numerous studies on bovine intramammary infection (IMI) or mastitis. S. chromogenes has been isolated most commonly in almost all studies but we couldn't isolate it in our study (Lange et al. 2015).

The presence of MRSA isolates in milk may surge a potential public health risk, and MRSA may spread between animals and humans due to many reasons like milk practice and improper hygiene maintenance. Spread of such microbes may be depending upon environmental condition in the herd. Virulence factors associated to this pathogen helps to protest against antimicrobial agents. The indiscriminate use of antibiotics/antimicrobials agents for therapeutic purpose could be the reasons for increased antimicrobial resistance of $S$. aureus. Different strains other than Staphylococcus spp. are also resistant to the antibiotics commonly used to treat all the microbes in therapeutic protocols of many human and animal infections. Further study on virulence factors and antimicrobial resistance genes may highlight the strain's response and strength in diverse condition during treatment with antimicrobials.

\section{Conclusion:-}

In this study eleven Coagulase positive methicillin resistant Staphylococcus aureus, six coagulase negative Staphylococcus spp. (two S. hominis, four S. pasteuri) and one Staphylococcus sp. having multidrug resistivity including methicillin were found from mastitis cases. Stimulatingly, obtained coagulase negative Staphylococcus sp. in this study are usually found in human origins, which leads us to understand that the mobile pathway of such pathogen into milk udders may be because of human activities during milking process. Increase in population of MRSA is affected by persistent use of antibiotics for treatment. Further study on virulence factors might help to understand the pathogenicity and treatment. Careful monitoring of the resistance status of $S$. aureus in dairy environments is needed, as Staphylococcus spp. transmission is dynamic and involves human approach, animal health, and likely the farm production environment.

\section{References:-}

1. Abd-Elrahman AH (2013) Mastitis in housed dairy buffaloes: Incidence, etiology, clinical finding, antimicrobial sensitivity and different medical treatment against E. coli mastitis. Life Sci J 10:532-538.

2. Bardiau M, Yamazaki K, Duprez J-N, et al (2013) Genotypic and phenotypic characterization of methicillinresistant Staphylococcus aureus (MRSA) isolated from milk of bovine mastitis. Lett Appl Microbiol 57:181-6. doi: 10.1111/lam.12099

3. Bergonier D, Sobral D, Feßler AT, et al (2014) Staphylococcus aureus from 152 cases of bovine, ovine and caprine mastitis investigated by Multiple-locus variable number of tandem repeat analysis (MLVA). Vet Res 45:1-8. doi: 10.1186/s13567-014-0097-4

4. Bhutto AL, Murray RD, Woldehiwet Z (2012) California mastitis test scores as indicators of subclinical intramammary infections at the end of lactation in dairy cows. Res Vet Sci 92:13-17. doi: 10.1016/j.rvsc.2010.10.006

5. Carey A, Duchon J, Della-Latta P, Saiman L (2010) The epidemiology of methicillin-susceptible and methicillin-resistant Staphylococcus aureus in a neonatal intensive care unit, 2000-2007. J Perinatol 30:135139. doi: $10.1038 / \mathrm{jp} .2009 .119$

6. Carles U, Trotonda MP, Monzo M, et al (2004) Role of Biofilm-Associated Protein Bap in the Pathogenesis of 
Bovine Staphylococcus aureus. 72:2177-2185. doi: 10.1128/IAI.72.4.2177

7. Coelho SMO, Pereira IA, Soares LC, et al (2011) Short communication: Profile of virulence factors of Staphylococcus aureus isolated from subclinical bovine mastitis in the state of Rio de Janeiro, Brazil. J Dairy Sci 94:3305-3310. doi: 10.3168/jds.2010-3229

8. Davis MP, Gamier P. (2013) The challenge of. Oncol (willist Park 27:190. doi: 10.1126/science. 1205711

9. Devriese L a, Van Damme LR, Fameree L (1972) Methicillin (cloxacillin)-resistant Staphylococcus aureus strains isolated from bovine mastitis cases. Zentralbl Veterinarmed B 19:598-605.

10. Embden DGJ Van, Barkema HW (2009) Clinical mastitis : incidence, etiology and treatment in organic and converting dairy herds Research Traineeship Faculty of Veterinary Medicine University of Utrecht Student : Supervisors : $1-15$.

11. Gómez P, Lozano C, González-Barrio D, et al (2015) High prevalence of methicillin-resistant Staphylococcus aureus (MRSA) carrying the mecC gene in a semi-extensive red deer (Cervus elaphus hispanicus) farm in Southern Spain. Vet Microbiol 177:326-331. doi: 10.1016/j.vetmic.2015.03.029

12. Haran KP, Godden SM, Boxrud D, et al (2012a) Prevalence and characterization of Staphylococcus aureus, including methicillin-resistant Staphylococcus aureus, isolated from bulk tank milk from Minnesota dairy farms. J Clin Microbiol 50:688-695. doi: 10.1128/JCM.05214-11

13. Haran KP, Godden SM, Boxrud D, et al (2012b) Prevalence and Characterization of Staphylococcus aureus, Including Methicillin-Resistant Staphylococcus aureus, Isolated from Bulk Tank Milk from Minnesota Dairy Farms. J Clin Microbiol 50:688-695. doi: 10.1128/JCM.05214-11

14. Harrison EM, Paterson GK, Holden MTG, et al (2013) A staphylococcus xylosus isolate with a new mecc allotype. Antimicrob Agents Chemother 57:1524-1528. doi: 10.1128/AAC.01882-12

15. Hijazin M, Ulbegi-Mohyla H, Alber J, et al (2011) Molecular identification and further characterization of Arcanobacterium pyogenes isolated from bovine mastitis and from various other origins. J Dairy Sci 94:1813-9. doi: 10.3168/jds.2010-3678

16. Kateete DP, Kimani CN, Katabazi FA, et al (2010) Identification of Staphylococcus aureus: DNase and Mannitol salt agar improve the efficiency of the tube coagulase test. Ann Clin Microbiol Antimicrob 9:23. doi: 10.1186/1476-0711-9-23

17. Khichar V, Kataria AK, Sharma R (2014) Characterization of Staphylococcus aureus of cattle mastitis origin for two virulence-associated genes (coa and spa). Comp Clin Path 23:603-611. doi: 10.1007/s00580-012-1657-5

18. Lange CC, Brito MAVP, Reis DRL, et al (2015) Sp from bovineecies-level identification of staphylococci isolated from bovine mastitis in Brazil using partial 16S rRNA sequencing. Vet Microbiol 176:382-388. doi: 10.1016/j.vetmic.2015.01.024

19. Lee GC, Long SW, Musser JM, et al (2015) Comparative whole genome sequencing of community-associated methicillin-resistant Staphylococcus aureus sequence type 8 from primary care clinics in a Texas community. Pharmacotherapy 35:220-228. doi: 10.1002/phar.1536

20. Makki AR (2011) Genotypic Characterization of Staphylococcus aureus Obtained from Humans and Bovine Mastitis Samples in India. doi: 10.4103/0974-777X.81686

21. Mullen KAE, Sparks LG, Lyman RL, et al (2013) Comparisons of milk quality on North Carolina organic and conventional dairies. J Dairy Sci 96:6753-62. doi: 10.3168/jds.2012-6519

22. Of O (2008) Isolation and Characterization of an Epidemic Methicillin-Resistant Staphylococcus aureus 15 Variant in the Central United States $\square$. 46:3548-3549. doi: 10.1128/JCM.00985-08

23. Oliveira LP De, Santana L, Silva VC, Cirqueira MG (2011) Study of Staphylococcus aureus in raw and pasteurized milk consumed in the Reconcavo area of the State of Bahia , Brazil. doi: 10.4172/21577110.1000128

24. Patel RJ, Pandit RJ, Bhatt VD, et al (2017) Metagenomic approach to study the bacterial community in clinical and subclinical mastitis in buffalo. Meta Gene 12:4-12. doi: http://doi.org/10.1016/j.mgene.2016.12.014

25. Patel S, Vaidya Y, Joshi C, Kunjadia A (2016) Culture-dependent assessment of bacterial diversity from human milk with lactational mastitis. Comp Clin Path 25:437-443. doi: 10.1007/s00580-015-2205-X

26. Prosperi M, Veras N, Azarian T, et al (2013) Molecular Epidemiology of Community- Staphylococcus aureus in the genomic era : a Cross-Sectional Study. 1-8. doi: 10.1038/srep01902

27. Saei HD (2012) Coa types and antimicrobial resistance profile of Staphylococcus aureus isolates from cases of bovine mastitis. Comp Clin Path 21:301-307. doi: 10.1007/s00580-010-1096-0

28. Shittu AO, Lin J (2006) Antimicrobial susceptibility patterns and characterization of clinical isolates of Staphylococcus aureus in KwaZulu-Natal province, South Africa. BMC Infect Dis 6:125. doi: 10.1186/14712334-6-125

29. Sumathi BR, Veeregowda BM, Gomes AR (2008) Prevalence and antibiogram profile of bacterial Isolates from 
clinical bovine mastitis. Vet World 1:237-238.

30. Trojan R, Razdan L, Singh N, et al (2016) Antibiotic susceptibility patterns of bacterial isolates from pus samples in a tertiary care hospital of Punjab, India. Int J Microbiol 2016:1-4. doi: 10.1155/2016/9302692

31. Türkyilmaz S, Tekbiyik S, Oryasin E, Bozdogan B (2010) Molecular epidemiology and antimicrobial resistance mechanisms of methicillin-resistant staphylococcus aureus isolated from bovine milk. Zoonoses Public Health 57:197-203. doi: 10.1111/j.1863-2378.2009.01257.x 